\title{
A method for the isolation of schistosome eggs and miracidia free of contaminating host tissues
}

\author{
J. P. DALTON ${ }^{1,2 *}$, S. R. DAY ${ }^{1}$, A. C. DREW ${ }^{1}$ and P. J. BRINDLEY ${ }^{1}$ \\ ${ }^{1}$ Molecular Parasitology Unit, The Queensland Institute of Medical Research, The Bancroft Centre, Post Office, Royal \\ Brisbane Hospital, Qld. 4029, and The Australian Centre for International and Tropical Health and Nutrition, Australia \\ ${ }^{2}$ School of Biological Sciences, Dublin City University, Dublin 9, Republic of Ireland
}

(Received 16 August 1996 ; revised 30 October 1996 and 15 Fanuary 1997; accepted 15 fanuary 1997)

SU M M A R Y

A novel method for the isolation of schistosome eggs and miracidia from livers of mice infected with Schistosoma japonicum or S. mansoni is described. The method employed collagenase B to degrade the interstitial matrix of mouse liver tissue, after which the schistosome eggs were separated from the liver cells by 2 single-step density centrifugations through Percoll. Using this procedure sufficient quantities of miracidia were obtained to generate a cDNA library. Southern blot analysis demonstrated that miracidia isolated by this method were free from contaminating host DNA.

Key words: Schistosoma mansoni, Schistosoma japonicum, eggs, miracidia.

\section{INTRODUCTION}

The pathology associated with chronic schistosomiasis mansoni and schistosomiasis japonica primarily results from granulomatous responses to eggs entrapped within the tissues and organs, particularly the liver and intestines, of the host (see Mitchell et al. 1994). Although the mediators that induce these $\mathrm{T}$ cell-dependent responses have not been defined, these are likely to be soluble egg antigens (Boros \& Warren, 1970; Colley, 1981; Wynn et al. 1995). Recent reports have also implicated proteolytic enzymes, such as cathepsin B and cathepsin L, released from schistosome eggs as being responsible for host liver pathology (Asch \& Dresden, 1979; Pino-Heiss, Brown \& McKerrow, 1985; McKerrow \& Doenhoff, 1988; Day et al. 1995).

Because of increasing interest in proteolytic enzymes of eggs and miracidia (Day et al. 1995), and the cDNAs encoding these proteases, there is now a requirement to isolate larval stages of schistosomes free of contaminating host tissues. The method described by Baltz et al. (1982) for the isolation of eggs from hamster liver employed both filtration and density-gradient centrifugation, and was an improvement from earlier procedures that involved tissue degradation with endogenous proteases or exogenous trypsin (Smithers, 1960; Browne \& Thomas, 1963; Asch \& Dresden, 1979; Pino-Heiss et al. 1985), sieving (Dresden \& Payne, 1981) and a combination of filtration and sedimentation (Coker

* Corresponding author: School of Biological Sciences, Dublin City University, Dublin 9, Republic of Ireland. Tel: +3531704 5407. Fax: + 3531704 5412. E-mail: daltonj@ccmail.dcu.ie.
\& Von Lichtenberg, 1956; Ritchie \& Berios-Duran, 1961; James \& Colley, 1974). However, in our laboratories we found that eggs isolated using the method of Baltz et al. (1982) remained contaminated with host tissue debris. While contamination with host tissues might be inconsequential for some applications, for instance for maintenance of the lifecycles, it can be problematic if the eggs and/or miracidia are to be used as a source of nucleic acids for construction of gene libraries or other molecular biology techniques. Indeed, the contamination of schistosome nucleic acids with mammalian sequences has been shown to occur frequently (Iwamura \& Irie, 1992; Irie \& Iwamura, 1993; Franco et al. 1995; Clough, Drew \& Brindley, 1996), the consequences of which have led to considerable controversy in interpretation of results claiming the presence of host-like sequences in the schistosome genome (Simpson \& Pena, 1991; Iwamura, Yonekawa \& Irie, 1995; Clough et al. 1996). Therefore, we undertook the development of an improved method for egg isolation, cognisant of the apparent shortcomings of the strategies that had been previously employed. We now report a procedure that proved to be reliable for the isolation of eggs free of host cell contamination.

\section{MATERIALS AND METHODS}

\section{Materials}

Polypropylene tubes were from Disposable Products, Technology Park, South Australia. Fifty ml Falcon tubes were purchased from Becton Dickinson Labware, Lincoln Park, NJ, USA. Collagenase B was from Boehringer Mannheim, Australia. Peni- 
cillin and streptomycin were purchased from CSL, Parkville, Australia. The Qiagen genomic columns were from Qiagen, Hilden, Germany, the HybondN nylon from Amersham, Sydney, NSW, Australia, and Percoll from Pharmacia, Uppsala, Sweden.

\section{Isolation of eggs from mouse livers}

Three to four livers from mice infected with $S$. mansoni or S. japonicum were chopped finely with a scalpel blade, and then blended to a smooth consistency in $50 \mathrm{ml}$ of phosphate-buffered saline (PBS). The suspension was decanted into a $50 \mathrm{ml}$ Falcon tube. Twenty mg collagenase B, $100 \mu \mathrm{l}$ $(10 \mu \mathrm{g})$ of penicillin and $100 \mu \mathrm{l}(20 \mu \mathrm{g})$ of streptomycin (CSL) were added to the tube, and the mixture incubated with shaking at $37^{\circ} \mathrm{C}$ overnight. The tube was then centrifuged at $400 \mathrm{~g}$ for $5 \mathrm{~min}$, the supernatant removed and the pellet resuspended in $50 \mathrm{ml}$ of fresh PBS. This wash procedure was repeated twice more, with the exception that after the final centrifugation the pellet was resuspended into $25 \mathrm{ml}$ of PBS. The resuspended mixture was passed through a $250 \mu \mathrm{m}$ sieve, and then a $150 \mu \mathrm{m}$ sieve. The filtrate was centrifuged at $400 \mathrm{~g}$ for $5 \mathrm{~min}$, the supernatant discarded and the pellet resuspended in $3 \mathrm{ml}$ of PBS and applied to the top of a Percoll column, prepared by mixing $8 \mathrm{ml}$ of Percoll with $32 \mathrm{ml}$ of $0.25 \mathrm{M}$ sucrose in a $50 \mathrm{ml}$ Falcon tube. The tube was centrifuged at $800 \mathrm{~g}$ for $10 \mathrm{~min}$. Liver cells remained on the top of the Percoll and were removed with a Pasteur pipette. The schistosome eggs, which pelleted tightly at the bottom of the tube, were then removed with a Pasteur pipette. Eggs were washed 3 times with PBS containing $1 \mathrm{~mm}$ EDTA, $1 \mathrm{~mm}$ EGTA in a $10 \mathrm{ml}$ tube at $30 \mathrm{~g}$. The metal chelators were included to inactivate the collagenase B. Residual liver cells were removed by discarding the supernatants. Further purification of eggs was achieved by resuspension in $0.5 \mathrm{ml}$ of $\mathrm{PBS}$ and application on to a second Percoll column, prepared by mixing $2.5 \mathrm{ml}$ of Percoll with $7.5 \mathrm{ml}$ of $0.25 \mathrm{M}$ sucrose in a $10 \mathrm{ml}$ polypropylene tube. The eggs were pelleted and then washed as before, with the exception that EDTA and EGTA were omitted from the wash buffers.

\section{Isolation of miracidia}

Eggs were added to $0.5 \mathrm{ml}$ of distilled water in a microfuge tube and exposed to a bright light (PinoHeiss et al. 1985). Miracidia hatched within $15 \mathrm{~min}$, and the supernatant was removed every $30 \mathrm{~min}$ for $2 \mathrm{~h}$ and replaced by fresh water. The supernatants containing the miracidia were pooled, chilled on ice (miracidia lose motility in cold water and sink to the bottom) and miracidia were then recovered by centrifugation at $15000 \mathrm{~g}$ for $20 \mathrm{sec}$ at $4{ }^{\circ} \mathrm{C}$ using an Eppendorf microcentrifuge.

\section{Southern hybridization}

We carried out Southern hybridization experiments in order to demonstrate whether genomic DNAs from miracidia purified by this procedure were free of contaminating host DNA and, by implication therefore, free of contaminating host cells. Mixedsex adults and miracidia of $S$. mansoni (Puerto Rican strain) were obtained from mice 7-10 weeks after an experimental infection with 100 cercariae. Genomic DNAs from these schistosomes were isolated by chromatography using Qiagen genomic columns according to the manufacturer's instructions. Rather than use the genomic DNAs in our Southern hybridizations, we employed the strategy of amplicon construction, as described by Lisitsyn, Lisitsyn \& Wigler (1993), in order to enhance the sensitivity of the hybridizations (Drew \& Brindley, 1995). The amplicon construction uses the polymerase chain reaction (PCR) to amplify 'representations' of genomic DNA. Hind III-derived amplicons were constructed from miracidial and adult schistosome DNAs as previously described (Drew \& Brindley, 1995). Approximately $1 \mu \mathrm{g}$ of each amplicon of genomic DNA was then separated by agarose gel electrophoresis and Southern transferred to Hybond$\mathrm{N}$ nylon by standard techniques. The nylon filter was then probed with a ${ }^{32} \mathrm{P}$-labelled, Hind IIIfragment of a mouse repetitive DNA (approximately 1000 copies/mouse genome encoding intra-cisternal A particle, Burt, Reith \& Brammar, 1984) isolated as described by Clough et al. (1996). The filter was subsequently stripped of this probe by boiling in $0 \cdot 1 \%$ SDS after which it was reprobed with a ${ }^{32} \mathrm{P}-$ labelled, Hind III-fragment of an S. mansoni repetitive sequence (GenBank accession no. U66336).

\section{RESULTS/DISCUSSION}

The procedure outlined above worked equally well for the isolation of S. mansoni and S. japonicum eggs. The yield of eggs was dependent on intensity of the schistosome infection but, as an indicator, we routinely obtained approximately $2000 \mathrm{eggs} /$ mouse liver obtained from animals 7 weeks after infection with 30 S. japonicum cercariae. Approximately $75 \%$ of the eggs hatched and released miracidia (Fig. 1). We have constructed a cDNA library in Uni-ZAP XR (Strategene, Integrated Sciences, Sydney, Australia) using mRNA isolated from 12500 miracidia obtained from 14 livers of S. japonicuminfected mice by employing the described procedure. The library was $>60 \%$ recombinant with an average insert size of $975 \mathrm{bp}$ and a titre of $3 \cdot 2 \times 10^{9} \mathrm{pfu} / \mathrm{ml}$.

The mouse intra-cisternal A particle sequence hybridized to sequences of host cell origin in the amplicon prepared from adult schistosome DNA (Fig. 2, lane 1). This observation was expected since 

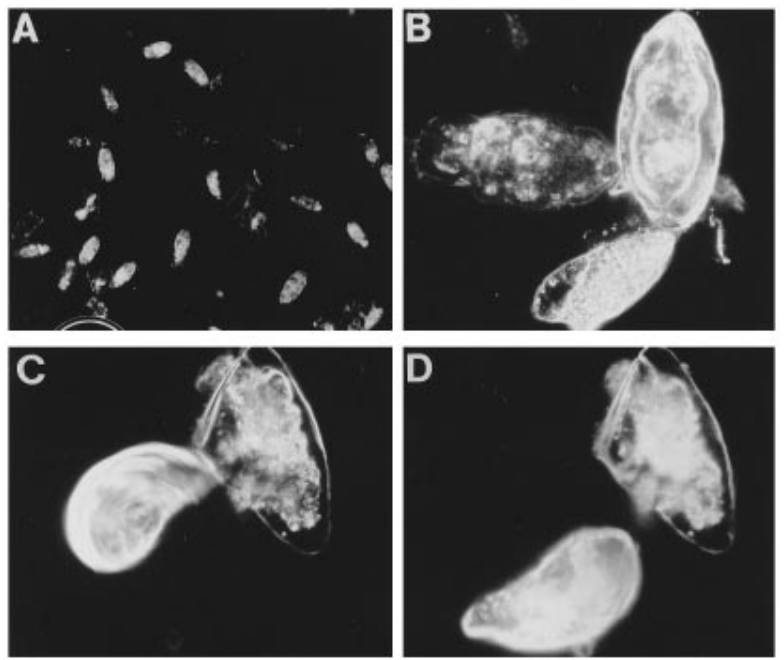

Fig. 1. Samples of purified eggs of Schistosoma mansoni viewed by microscopy $(\times 200)(A)$. Under high power fully embryonated miracidia can be observed (B). Miracidia hatch from the eggs within 5 min of placing eggs in water (C and D).

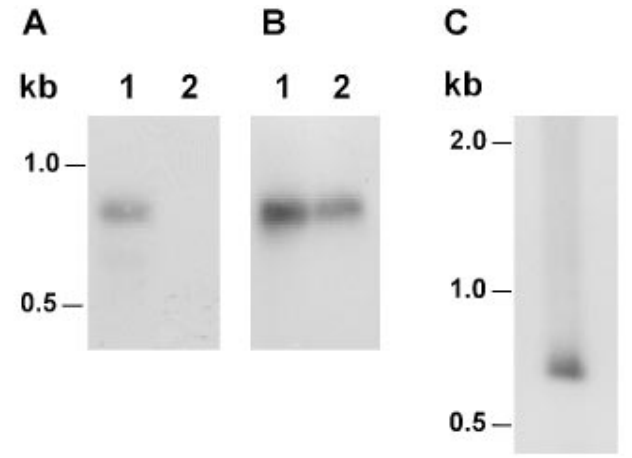

Fig. 2. Southern blotting analysis of schistosome adult and miracidial DNAs. Adult (lanes 1) and miracidial (lanes 2) Schistosoma mansoni Hind III amplicons were probed with a cloned fragment of DNA from the mouse intra-cisternal A particle (A) and a cloned S. mansoni repetitive DNA fragment (B). Mouse genomic DNA digested with Hind III and probed with the mouse intra-cisternal A particle served as a positive control (C).

adult worm DNA preparations are often contaminated with host DNA (see Clough et al. 1996). In contrast, this probe did not hybridize to the miracidial amplicon DNA (Fig. 2, lane 2). The $S$. mansoni repetitive sequence hybridized to both adult and miracidial amplicon DNAs at a comparable level (Fig. 2, lanes 1 and 2), which indicated that the differences in the level of host DNA hybridization were not due to differences in quantity of DNA in the separate lanes. Taken together, these data showed that miracidia purified by our method contained no detectable, contaminating host DNA and, therefore by extension, no contaminating host cells.

In summary, this paper describes a methodology for the isolation of S. mansoni and S. japonicum eggs from mouse livers. The method takes advantage of the substrate specificity of the metalloproteinase collagenase $\mathrm{B}$ for the digestion of interstitial collagen, which has long been employed in methods for the isolation of hepatocytes (Tager, Rubenstien \& Steiner, 1975). When livers from schistosomeinfected mice are incubated overnight with this enzyme a fine suspension of eggs and cells is obtained. The eggs can then be separated from host cells by sieving followed by centrifugation through a single layer of Percoll. Sufficiently pure eggs for experiments such as those that investigate egg hatching can be obtained using a single Percoll purification step. However, eggs and miracidia which are totally free of detectable contamination with host tissues can be obtained by employing a second Percoll purification. In our laboratory these procedures provided sufficient material to allow the preparation of a miracidial cDNA library. We consider that the procedure outlined here should be of use for the identification and characterization of the schistosome egg antigens (particularly by recombinant DNA techniques), including those that are apparently responsible for the hepatic fibrosis associated with schistosomiasis mansoni and schistosomiasis japonica.

We thank Mary Duke for the maintenance of the schistosome life-cycles. We acknowledge the financial assistance of the Australian National Health and Medical Research Council and Dublin City University.

\section{REFERENCES}

ASCH, H. L. \& DRESDEN, M. H. (1979). Acidic thiol proteinase activity of Schistosoma mansoni egg extracts. Fournal of Parasitology 65, 543-549.

BALTZ, T., LACASSIE, I., TRIBOUley-DURET, J. \& TRIBOUley, J. (1982). Density-gradient separation of Schistosoma mansoni eggs. Fournal of Parasitology 68, 963-965.

BOROS, D. L. \& WARREN, K. s. (1970). Delayed hypersensitivity-type granuloma formation and dermal reaction induced and elicited by a soluble factor from Schistosoma mansoni eggs. Fournal of Experimental Medicine 132, 488-507.

BRowne, H. G. \& THOMas, J. I. (1963). Method for the isolating, pure, viable schistosome eggs from host tissues. Fournal of Parasitology 49, 371-374.

BURT, D. W., REITH, A. D. \& BRAMmar, W. J. (1984). A retroviral provirus closely associated with Ren-2 gene of DBA/2 mice. Nucleic Acids Research 12, 8579-8593.

Clough, K. A., DREW, A. C. \& BRINDley, P. J. (1996). Hostlike sequences in the schistosome genome.

Parasitology Today 12, 283-286.

COKER, C. M. \& VON LICHTENBERG, F. (1956). A revised method for isolation of Schistosoma mansoni eggs for biological experimentation. Proceedings of the Society for Experimental and Biological Medicine 92, 780-782. COLLEY, D. G. (1981). T lymphocytes that contribute to the immunoregulation of granuloma formation in the chronic murine schistosomiasis. Fournal of Immunology 126, 1465-1468.

DAY, S. R., DAlton, J. P., ClOUGh, K. A., LEONARdo, L., TIU, W. U. \& BRINDLEY, P. J. (1995). Characterization 
and cloning of the cathepsin $\mathrm{L}$ proteinases of Schistosoma japonicum. Biochemical and Biophysical Research Communications 217, 1-9.

DRESDEN, M. H. \& PAYNE, D. C. (1981). A sieving method for the collection of schistosome eggs from mouse intestines. Fournal of Parasitology 67, 450-452.

DREW, A. C. \& BRINDLEY, P. J. (1995). Female-specific sequences isolated from Schistosoma mansoni by representational difference analysis. Molecular and Biochemical Parasitology 71, 173-181.

FRANCO, G. R., ADAMS, M. D., SOARES, M. B., SIMPSON, A. J., VENTER, J. C. \& PENA, S. D. (1995). Identification of new Schistosoma mansoni genes by the EST strategy using a directional cDNA library. Gene 152, 141-147.

IRIE, Y. \& IWAMURA, Y. (1993). Host-related DNA sequences are localized in the body of schistosome adults. Parasitology 107, 519-528.

iWAMURA, Y. \& IRIE, Y. (1992). Heterogeneity of hostrelated DNA sequences in schistosomes. Parasitology Today 8, 90.

IWAMURA, Y., YONEKAWA, H. \& IRIE, Y. (1995). Detection of host DNA sequences including the H-2 locus of the major histocompatibility complex in schistosomes. Parasitology 110, 163-170.

JAMES, S. L. \& COLlEY, D. G. (1974). A method for the isolation of Schistosoma mansoni eggs. Fournal of Parasitology 60, 1043-1044.

Lisitsyn, N., Lisitsyn, N. \& Wigler, M. (1993). Cloning the differences between two complex genomes. Science 259, 946-951.

McKerrow, J. H. \& Doenhoff, M. J. (1988). Schistosome proteases. Parasitology Today 4, 334-340.
Mitchell, G. F., GARCia, E. G., Rivera, P. T., TIU, W. U. \& DAVERN, K. M. (1994). Evidence for and implications of anti-embryonation immunity in schistosomiasis. Experimental Parasitology 79, 546-549.

PINO-HEISS, S., BROWN, M. \& McKERROW, J. H. (1985). Schistosoma mansoni: degradation of host extracellular matrix by eggs and miracidia. Experimental Parasitology 59, 217-221.

RITCHIE, L. S. \& BERIOS-DURAN, L. A. (1961). A simple procedure for recovering schistosome eggs in mass from tissues. Fournal of Parasitology 47, 363-365.

SIMPSON, A. J. G. \& PENA, S. D. J. (1991). Host-related DNA sequences in the schistosome genome. Parasitology Today 7, 266.

SMithers, s. R. (1960). The isolation of viable schistosome eggs by a digestion technique. Transactions of the Royal Society of Tropical Medicine and Hygiene 54, 58-70.

TAGER, H. S., RUBENSTIEN, A. H. \& STEINER, D. F. (1975). Methods for the assessment of peptide precursors. Studies on insulin biosynthesis. Methods in Enzymology 37, 326-345.

WynN, T. A., CHEEVER, A. W., JANKOVIC, D., POINDEXTER, R. W., CASPAR, P., LEWIS, F. A. \& SHER, A. (1995). An IL-12-based vaccination method for preventing fibrosis induced by schistosome infection. Nature, London 376, 594-596.

Yoshino, T. P., LODES, M. J., REGE, A. A. \& CHAPPELL, C. L. (1993). Proteinase activity in miracidia, transformation excretory-secretory products, and primary sporocysts of Schistosoma mansoni. Fournal of Parasitology 79, 23-31. 